\title{
STABLE DETERRENCE AND ITS LIMITS
}

\author{
J. DAVid Singer \\ University of Michigan
}

$\mathrm{T}$

HERE WAS A HAPPY TIME, not too long ago, when the major dialogue on national arms policy was between the armers and the disarmers. The issue, at least in much of the public's mind, was whether the nation ought to pursue a policy of negotiated comprehensive disarmament or one of national preparedness. There were those who believed that all arms races must eventuate in war, and those who believed that military superiority was the best guarantee of peace.

But in recent years, this easy dichotomy has given way to a far more complicated picture. Both the armers and the disarmers have become increasingly sophisticated, and as a result have divided into a welter of sub-factions, each advocating a national security policy differing only slightly from that of its neighbor on the arms policy continuum. Though this fragmentation has led to a disconcerting muddying of the polemic waters, it must be viewed as a healthy and encouraging development. And even if one can hardly contend that the vast verbal and intellectual gap between the "tough" and the "soft" has been completely bridged, we are certainly moving in that direction. As a consequence, it is now more possible to engage in vigorous and meaningful discourse rather than to restrict ourselves to the vacuous and loaded exchanges of "soft-on-communism" or "warmonger."

\section{The Armament-Disarmament Synthesis}

There is, however, one consequence of this nascent public sophistication which - to this writer, at least - appears as a mixed blessing. As the advocates of gross, crude, and indiscriminate stockpiling of any and all varieties of military hardware have given way to the new sophistication in strategic doctrine, they have also succeeded in dividing the ranks of those who had once been ardent advocates of multilateral, comprehensive disarmament.

This they have been able to accomplish for two sets of reasons. First, by acquiring and expressing a belated awareness of the risks of nuclear strategy and weapons preparedness, they have appeared more humane, intelligent, and cautious than their progenitors. And out of this awareness has emerged a remarkably thoughtful and imaginative strategic discourse, in which at least some of the relations between technology and psychology seem to have been understood. ${ }^{1}$

NoTE: This article, written while the author was consultant in International Relations at the United States Naval War College, is based on Part II of a forthcoming book entitled Deterrence, Arms Control and Disarmament: Toward a Synthesis in National Security Policy. Neither the article nor the full-length study necessarily reflects the official views of the War College or the Navy.

${ }^{1}$ Among these are Thomas C. Schelling and Morton H. Halperin, Strategy and Arms Control (New York: Twentieth Century Fund, 1961); Hedley Bull, The Control of the Arms Race (New York: Praeger, 1961); Edouard Le Ghait, No Carte Blanche to Capricorn (New York: Bookfield House, 1960); Herman Kahn, On Thermonuclear War (Princeton: Princeton University Press, 1960); Glenn H. Snyder, Deterrence and Defense (Princeton: Princeton 
Moreover, by shifting their focus from "defense" to "deterrence," the advocates of preparedness have revealed an understanding of the limits of weapons as the shield of national security, and have frankly pursued (with, of course, some notable exceptions) a prevent-the-war strategy rather than a win-the-war strategy. ${ }^{2}$ In the same vein, they have substituted reason and calculation in place of blood and thunder; whereas the early armers spoke of the Soviets in emotion-ridden terms, waging a holy crusade against the vicious and godless infidel, the new breed envisages the adversary as a competent, calculating planner who might even have some legitimate security interests himself. This sort of stance was bound to modify the initial distrust and implacable fear which the disarmers felt toward the armers. Clearly they had become men of peace.

The second set of reasons for the emerging rapprochement may be found within the experiences and discoveries of the disarmers themselves. Fifteen years of fruitless negotiation have brought the disarmament advocates to a belated awareness of certain harsh realities of international life. They have discovered how complicated the negotiations must be and how complicated and costly any effective arrangement must be; ${ }^{3}$ the technical and political obstacles to inspection alone have become more fully appreciated. ${ }^{4}$ Furthermore, there has been a gradual realization that any comprehensive disarmament, to be safe and effective, demands radical modifications in the traditional notions of national sovereignty. Finally, any original optimism about Soviet cooperativeness has been painfully altered; the disarmers have discovered that it takes two to negotiate successfully.

It has been this concatenation of developments which led inexorably to a coming together of many of the armers and the disarmers. As the articulate and concerned thinkers on each side of the debate discovered that the others were neither insane nor irresponsible, they found that their differences were not as great as had been imagined. And out of this dialectic, therefore, has emerged the rudiment of a new synthesis, and that synthesis seems to be taking shape under a rubric which is called "arms control."

At this point, however, some verbal sleight-of-hand manifests itself. By "arms control" one might reasonably mean some inspected limitation or reduction on the quantities, types, and dispositions of the national weapon systems -

University Press, 1961); Arthur Hadley, The Nation's Safety and Arms Control (New York: Viking Press, 1961); Oskar Morgenstern, The Question of National Defense (New York: Random House, 1959); Bernard Brodie, Strategy in the Missile Age (Princeton: Princeton University Press, 1959); and Wayland Young, Strategy for Survival (Middlesex [U.K.]: Penguin Books, 1959).

${ }^{2}$ Though he himself is ambivalent on this score, I would classify Kahn, op. cit., in the latter category.

${ }^{3}$ The most detailed analysis of these negotiations is in Bernard G. Bechhoefer, Postwar Negotiations for Arms Control (Washington: Brookings Institution, 1961). Briefer, but perhaps more insightful, is Richard J. Barnet, Who Wants Disarmament? (Boston: Beacon Press, 1960). On the matter of nuclear weapons and fissionable material, see Joseph L. Nogee, Soviet Policy Toward International Control of Atomic Energy (Notre Dame: University of Notre Dame Press, 1961).

'On the technical problems, see Seymour Melman (ed.), Inspection for Disarmament (New York: Columbia University Press, 1958), and Bernard T. Feld, Technical Problems of Arms Control (New York: Institute for International Order, 1960). On the political difficulties, see Louis Henkin, Arms Control and Inspection in American Law (New York: Columbia University Press, 1958). 
negotiated partial disarmament. But that would be a premature conclusion, as the following not-wholly-imaginary dialogue should illustrate.

Sophisticated Armer: Wouldn't a totally disarmed world be quite dangerous? What if one side manages to retain just a few strategic weapons?

Disenchanted Disarmer: How awfull They could blackmail us with ease.

Sophisticated Armer: And haven't the negotiations demonstrated how unrealistic it would be to expect total disarmament anyway?

Disenchanted Disarmer: I'm afraid so. We'll have to go one step at a time.

Sophisticated Armer: Exactly. And as we disarm step by step, what is our greatest problem?

Disenchanted Disarmer: That one side doesn't gain a military advantage at any stage.

Sophisticated Armer: Certainly. How can this be assured?

Disenchanted Disarmer: By moving slowly, taking all necessary precautions, and keeping the rest of our weapons at the ready. No stage must be permitted to lead to instability in the stand-off.

SophistiCATED ARMER: How perspicacious! Stability is crucial all the way and we must not lose our ability to deter them from violations or surprise attack. After all, we still can't trust them.

Disenchanted Disarmer: Of course not. We must deter them from upsetting the stability. But we don't even have that capacity now.

Sophisticated Armer: Well, there is room for improvement, and perhaps we ought to acquire a better deterrent before going too far in arms reduction.

Disenchanted Disarmer: Yes, let's see what we can negotiate in order to stabilize our balance of terror.

Sophisticated ARMER: But didn't you say that negotiations are most difficult with those people? Isn't there much that we can do unilaterally?

Disenchanted Disarmer: Certainly, let's get on with it.

Out of this dialogue, ${ }^{5}$ therefore, emerges a somewhat unexpected definition of arms control. The author of the introductory paper for a recent conference on arms control suggested that "it is useful to think generally of arms control as a cooperative or multilateral approach to armament policy - where armament policy includes not only the amount and kind of weapons and forces in being, but also the development, deployment and utilization of such forces. ..." In the next sentence he refers to the improvement of the nations' security "by adjusting at least some armament capabilities and uses. ..." ${ }^{6}$ Thus, from the

\footnotetext{
In addition to the many published books cited above, there have been numerous conferences, and a spate of articles and unpublished memoranda on arms control in the past year or so and this dialogue is based on participation in several of these conferences and a reading of almost all the books, articles, and papers. Another indication of the popularity of arms control is to be found in the shifting distribution of articles in such journals as the Bulletin of the Atomic Scientists.

'Donald G. Brennan, "Setting and Goals," Daedalus (Special Issue on Arms Control), Fall 1960, pp. 692-93. This issue is comprised of the papers presented at the American Academy of Arts and Sciences conference (financed by the Johnson Foundation) in May 1960.
} 
elimination or reduction of national armaments we have slipped to the more modest concern of "adjustments" in the development, deployment and utilization of these armaments. And as for the element of negotiation, we replace it with "the cooperative or multilateral approach," and as everyone knows, cooperation need not necessarily imply formal negotiation. ${ }^{7}$ By tacit communication and informal agreement we and the Soviets can work out, on a unilateral basis, certain multilateral arrangements which will enhance the stability of the nuclearmissile standoff. Mutual calculations of self-interest will suffice. Certainly, it is argued, this is preferable to those long, drawn-out, and frustrating conferences which succeed only in raising tensions and generating further mistrust.

Having thus dispensed with both the disarmament and the negotiation, our newly sophisticated armers and disarmers can get down to the main order of business: the development of a stable deterrence relationship. In this neat and antiseptic pursuit, we are free to ignore such messy factors as ideology, irrationality, domestic politics, and third-party interference. Here we need only concern ourselves with computer-type players and weapons technology, with the latter apparently the more important. As one of our most thoughtful advocates of stable deterrence has argued, "the impossibility of war has to be of a technological character." 8 What, then, is this fascinating new preoccupation, and what are the principal elements? What is it that our one-time disarmament advocates seem to be on the verge of embracing?

\section{Stable Deterrence and InVUlnerability}

If there is a single key concept in the stable deterrence strategy it is that of the "invulnerable retaliatory force"; from this all else flows. If one's retaliatory or strike-back capability is made invulnerable to any kind of first strike by the adversary, he has a highly stable deterrent. This is because the potential attacker will know that no matter how much surprise, speed, accuracy, or megatonnage he puts into his first blow, there will always be enough of the victim's retaliatory power left undamaged to permit him to strike back at the attacker's cities with punitive devastation.9 ${ }^{9}$ The certainty of such reprisal will, of course, deter any rational decision-maker, no matter how hostile his intentions, from ever launching his attack in the first place.

\section{Invulnerability and passive protection}

Granted the desirability of achieving this invulnerability of one's retaliatory capability, how does one go about it? Bascially, there are six different passive

\footnotetext{
'This view is most cogently and persuasively expressed by Thomas C. Schelling and Morton Halperin, The Strategy of Conflict (Cambridge: Harvard University Press, 1960).

${ }^{8}$ Morgenstern, op. cit., p. 296. Italics added.

- There is a school of thought that believes that the mere destruction of most or all of his cities and industrial complexes may not be enough to deter a potential nuclear aggressor, and that the deterrer's retaliatory strike must be able to hit the attacker's launching sites, air strips, staging areas, and naval bases, as well. This is commonly referred to as a "counter-force" capability, as distinguished from the more modest "counter-city" or "finite" capability. Of course, a counter-force capability is also a fine strike-first capability, and its acquisition might well be so provocative as to trigger the attack it was designed to deter. In this regard, see my critique of the Kahn position in J. David Singer, "The Strategic Dilemma: Probabilities versus Disutilities," Journal of Conflict Resolution, 5 (June 1961), 197-205.
} 
means of making one's strike-back forces invulnerable: numbers, hardening, dispersal, distance, concealment, and mobility. Let us examine each technique briefly. By numbers, we refer to increasing the quantity of missiles, aircraft, or other delivery system to such a degree that no matter how many warheads or bombs the attacker delivers, it is always less than enough to destroy "enough" of those possessed by the victim; those that are left because of the attacker's numerical inferiority may then be launched on their mission of retaliation. This is one of the least attractive means of acquiring invulnerability, for two reasons. First, one is never sure how many delivery vehicles are needed for an "exchange ratio" which gives the deterrer a numerical superiority over the potential attacker, and second, either side can make it extremely costly to the other by engaging in a straight quantitative arms race, with no reasonable upper limits. ${ }^{10} \mathrm{~A}$ second, and only slightly less attractive device for the deterrer is to engage in "hardening" one's retaliatory forces. By placing missile pads or airplane hangars underground or under some form of protective shelter, one can hope that the attacker will be unable to get enough direct hits and near misses to destroy very many; those remaining after the attack may then be brought out into the open, and fired against the attacker's cities (assuming, again, a finite counter-city strategy only). There are two major disadvantages of the hardening approach. One is that it is nearly impossible to build any shelter to withstand a direct hit and only slightly easier to protect against a near miss; even as the highly accurate manned bomber is phased out and replaced with the missile, the latter's guidance system improves steadily, as do the charts and maps upon which guidance depends. Secondly, as rocket thrust continues to rise, there is almost no limit to the size warhead that can be carried over intercontinental distances, and the attacker can therefore afford to increase his yield and blast effect in order to keep ahead of the hardening process. The harder the site, the bigger the warhead it will attract, and also the more fallout, heat, and blast destruction the environs will probably receive.

A third, and somewhat more attractive approach, is that of dispersal. If the deterrer has adequate numbers of strike-back weapons and merely spreads them out over vast geographical areas, he compels the attacker to disperse his efforts, too, and reduces the likelihood that all reprisal forces will be destroyed during a first strike. The Strategic Air Command is now engaged in a belated dispersal of its retaliatory bomber force both at home and overseas, but it poses serious logistic, communication, and morale problems and is far more expensive than a consolidated deployment. Furthermore, for dispersal to be effective, it must still be based on impressive quantity. For any retaliatory system to be effective as a deterrent, it must have a sum of vehicles equal to: the number required to mete out "adequate" (or, to the deterree, "unacceptable") punishment, plus the number likely to be destroyed by any surprise attack, plus the number likely to fail in launching, plus the number likely to be intercepted en route, plus the number

\footnotetext{
${ }^{10}$ Some suggestive and useful calculations of this "exchange ratio" are found in a pair of unpublished monographs. See, John B. Phelps et al., "Some Calculations on Counterforce Strategies in a General Nuclear War," and Raymond Foye et al., "Counterforce Calculations Attack and Retaliation with Mixed Weapon Systems" (Columbus: Mershon National Security Program, 1959).
} 
likely to miss their targets. This total cannot help but be awesome in its size, cost, and provocativeness.

Another technique for increasing the likelihood of one's strike-back forces surviving a first strike is to place them at maximum distance from the potential attacker's launch sites. For attacking manned aircraft, range is a distinctly limiting factor, even if it does nothing more than restrict the size of the payload in order to make room for additional fuel. And for the present generation of missiles, increased range leads to a significant diminution of accuracy; this being a function of incomplete mapping and charting as well as still-evolving guidance systems. The closer your sites are to those of the attacker, the more vulnerable they are; Thor and Jupiter IRBM's in Turkey, Italy, and Britain are an example. On the other hand, moving away from your adversary's launch sites is often not practicable, especially if your own retaliatory vehicles are of short range or inadequate guidance. And often the sites which are most advantageous in terms of distance are least advantageous in terms of such factors as proximity to cities, factories, and transport centers or accessibility to logistic support. Of course, when retaliatory weapons are mounted in space satellites, the deterrer will have achieved the penultimate in distance as well as dispersal and mobility, which are discussed below.

Over against these four rather primitive means of diminishing vulnerability, there are two other techniques which are just becoming technologically possible; one is mobility and the other is concealment. Until the prospective attacker can locate his victim's strike-back forces, he cannot even begin to destroy them; clandestine moving of delivery vehicles from one site to another, concealment, or a combination of mobility and concealment can make location and detection of strike-back weapons extremely difficult and thus reduce the probability of their being destroyed. In nations which are near the "closed" end of the open-closed continuum, concealment is not particularly difficult; the normal channels through which target information might be ascertained in open-type societies are essentially unavailable in the U.S.S.R. and its East European allies, for example. While the Soviets probably know the location of almost every airfield and missile site in North America and Western Europe, we must rely on such elaborate intelligence operations as U-2 overflights and reconnaissance satellites in order to acquire similar information regarding their launch sites. The inaccessibility of this information is a distinct asset to them (and as I hope to suggest later, to us as well) which they are most reluctant to vitiate by "open skies" or any other inspection scheme. But since our sites are known and thus relatively vulnerable to surprise attack, we must turn to other versions of the mobility-concealment ploy. Perhaps the most dramatic result of this effort is the now operational fleet ballistic missile system - the nuclear-powered submarine equipped with sixteen Polaris IRBM's capable of carrying a nuclear warhead about 1,500 miles. ${ }^{11}$ At this writing, only four such submarines are operating, but twenty have been authorized, and the Navy is seeking at least forty-five.

${ }^{11}$ The range of the George Washington's missiles is announced as 1,200 miles, but the Navy is giving high priority to increasing that figure considerably in subsequent vessels. 
Another attempt to deprive the Soviets of launching site location information is the solid-fueled Minuteman ICBM; though some reports had it that this weapon (expected to be operational in July 1962) could be fired from railroad flat cars, it will be somewhat less mobile. Under present plans, there will be a great many launching sites along railroad lines and fewer missiles, and these latter will be moved frequently (but randomly) from one site to another, reducing the probability of the Soviets knowing the location of most of them at any given moment. And until the B-52 and B-58 manned bombers have disappeared from our retaliatory arsenal, their vulnerability will be somewhat reduced by keeping a certain percentage of them aloft at all times. This latter combination of dispersal, mobility, and limited concealment is designed to assure the survival of enough strike-back planes to make the threat of retribution credible. But it, too, poses certain difficulties. First of all, it is extremely expensive and it requires duplicate crews. Secondly, these airborne carriers of nuclear weapons have crashed in the past, and in any subsequent crash its payload could conceivably be detonated, despite many precautions in design and arming mechanisms. Thirdly, from the Kremlin's point of view an airborne SAC is highly threatening and provocative.

These then are some of the passive steps by which the deterrer may reduce the vulnerability of his retaliatory forces, make his threat of reprisal credible, and keep the deterrent relationship stable. It must be borne in mind that this relationship is supposed to be relatively symmetrical and basically reciprocal, and that the Soviet is also pursuing a strategy of stable deterrence. Though this is a widespread assumption (or hope) among stable deterrers in the West, it may not be altogether true, and we must not forget that when one side is less conservative, more daring, and less predictable, he enjoys a certain bargaining advantage over his more cautious opponent.

\section{Early warning and active protection}

In addition to these relatively passive vulnerability-reducing measures, there are two other kinds of action which the deterrer may pursue in maximizing the certainty of reprisal against his attacker. One is the institution of an early-warning system, and the other is the development of interception or counter-measure instruments. Under the first category the West already has the DEW Line, MidCanada and Pine Tree radar nets, designed primarily for the early detection of manned bombers at high altitudes and coming from the North Polar regions; there is also a fairly elaborate radar net in Europe. And just as the first Soviet missiles began to appear on station in numbers, we completed the basic BMEWS (Ballistic Missile Early Warning System) installation. To these ground-based warning systems must be added several new developments of which we will be hearing much in coming months. One will be the dramatic back-scatter radar (growing out of the Navy's Project Tepee), capable of detecting missile launchings instantaneously at inter-continental ranges. This system will give almost thirty minutes warning time against the ICBM, as compared with about ten minutes which the BMEWS net can offer. In outer space, we will soon have supplementary early warning systems provided by such reconnaissance satellite 
systems as Midas and Samos, and to a lesser extent, Tiros. Finally, there is the airborne patrol system, in which manned and radar-equipped aircraft search the areas which are not adequately covered by the other devices.

The importance of all these early warning systems to the preservation of one's retaliatory force and hence to the stability of the deterrent cannot be exaggerated. The more time there is available between warning and impact, the more likely you are to be able to disperse or protect your strike-back capability. It also offers the opportunity to get your retaliatory weapons off the ground and headed toward their targets in the attacker's zone of the interior. And the more certain he is that you can both preserve your forces and strike back, the less likely he is to strike in the first place. Also significant is the role of early warning as a source of negative intelligence. That is, the more reliably one can know that the other is not launching, the less likely one is to "pre-empt" in error. Thus early warning systems fulfill a dual function. ${ }^{12}$

As was mentioned earlier, there is still a third general approach to the preservation of one's retaliatory forces, and that is the active destruction of the attacker's vehicles. Of course, the easiest point at which to destroy them is on their airstrips or launching sites, and the ICBM is thus in this sense also an effective anti-missile weapon. But this is being rather facetious, and it makes little sense to start the nuclear exchange which you are dedicated to prevent. There are, however, two general techniques which it is hoped will contribute to stable deterrence by posing a threat to attacking ICBM's: electronic counter-measures and the anti-missile missile. Neither technique is anywhere near solution at this date, and even if feasible, they are several years away. ${ }^{13}$

So far we have discussed the problem of stabilizing the deterrent balance by means of protecting the deterrer's retaliatory forces so that no matter how the would-be attacker plans he cannot expect to be free from devastating nuclear reprisal. This awareness, it is hoped, will deter him from striking in the first place.

\section{Provocation and Stability in Deterrence}

But no matter how much we would wish it otherwise, acquiring "invulnerability" is only a part (albeit an important part) of the requirement of stable mutual deterrence, and recent months have revealed a promising concern for some of the other requirements on the part of those involved in the study and practice of deterrence. A second and equally crucial part of the stability problem is that of provocation. In other words, a stable balance requires that we not only reduce the positive incentives and attractiveness of a strike-first strategy, but that we also reduce the negative motivation or sense of necessity on the part of a would-be nuclear aggressor. To illustrate: unless the other side is inevitably and

\footnotetext{
${ }^{12}$ This point is imaginatively developed in Thomas C. Schelling, "Arms Control: Proposal for a Special Surveillance Force," World Politics, 13 (October 1960), 1-18.

${ }^{13}$ Experience in weapons development suggests that a period of about eight years is required between the theoretical solution of a problem and the production of the first piece of hardware. Moreover, just as there are counter-measures, there are counter-counter-measures. A useful discussion of the problem is in Arnold Wolfers et al., Developments in Military Technology and Their Impact on U.S. Strategy and Foreign Policy (Washington: Senate Foreign Relations Committee, Study No. 8, 1959). See also, J. David Singer, "Weapons Technology and International Stability," Centennial Review, Vol. 5 (Fall, 1961), 415-35.
} 
inexorably bent on a nuclear attack, there is much that can be done to influence him in either direction. The deterrer can develop a weapons mix or a doctrine which makes the adversary believe that the "deterrent" is merely a cover behind which an actual offensive strategy is unfolding or he can generate an image of pure defense and retaliation only. If the men in the Kremlin were to begin to believe that we plan a first strike at some particular date, this belief could easily provoke them into a "preventive" attack, despite the other costs and risk involved. Such is the present nature of military technology that he who strikes first derives considerable advantage. ${ }^{14}$ One way to reduce the temptation of a first strike is by weapons design and early warning; the other is by persuading the adversary that you have no intention of exploiting it yourself.

What are some of the things each side can do to generate such a belief in the camp of the other, without at the same time weakening its own strategic posture? Perhaps one of the most promising is to eschew the building and deployment of weapons whose objective characteristics are as much (or more) strike-first as strike-back. The more vulnerable a new weapon is the more likely the other side is to view it as a first strike device, since it has almost no strike-back potential. American IRBM sites in Britain, Italy, and Turkey are of such a nature: within easy range of Soviet aircraft or IRBM's, above ground, and almost unprotected, these weapons are as much a provocation as a deterrent.

Conversely, the attempt to make invulnerable those elements which have little or no retaliatory usefulness could also be provocative to the other side. Thus any large-scale program of civil defense or underground factory-building would tend to have a strongly provocative influence. ${ }^{15}$ Despite rumors and allegation to the contrary, there is little evidence of Soviet activity in these realms, and this is a good omen. If either side were to push such programs, the other would have to make one of two assumptions: either the first is planning a first strike and wants to reduce the destructiveness of the retaliatory blow, or it is so sure that the second is definitely planning an attack that it must reduce the losses sustained in the inevitable blow. This latter belief, if conveyed to the other side, might well convince them that the first is so sure of inevitable showdown that it might be tempted to get in the original blow itself; the fatal and spiraling instability of such reciprocal expectations should be obvious. Some may contend that protection of civil populations and industrial plants actually reduces the incentive to strike, by minimizing the amount of damage that can be done, ${ }^{16}$ but this reasoning smacks of the old and more simple-minded approach discussed in

${ }^{14}$ There has been continuing speculation in the West as to whether the Soviet planners now accept this proposition. Under Stalin, the advantages of initiative and surprise in military doctrine were discounted in contrast to the "permanently operating factors." Two recent books, with somewhat differing conclusions on this matter are: Herbert S. Dinerstein, War and the Sovict Union (New York: Praeger, 1959); and Raymond Garthoff, Soviet Strategy in the Nuclear Age (New York: Praeger, 1958).

${ }^{15}$ See J. David Singer, "Deterrence and Shelters," Bulletin of the Atomic Scientists, 17 (October 1961) 310-15, for a development of this argument.

${ }^{10}$ It should also be noted that the actual usefulness of such shelters in the event of any nuclear exchange is a matter of considerable doubt. Certainly it would reduce - depending on warning time - the number of immediate casualties due to fall-out, blast, and heat, but the degree of over-all protection may be, in the long run, negligible. It should also be remem. 
the opening paragraphs. It fails to explore the matter of reciprocal preceptions and thus to distinguish between deterrence and provocation. Difficult as it may be, both sides must - if deterrence is really their doctrine - be willing to sacrifice certain win-the-war capabilities in order to enhance their prevent-the-war posture; such willingness is the hallmark of the new deterrent advocates. ${ }^{17}$

As a matter of fact, this writer is so convinced of the importance of avoiding developments which are strongly provocative that he would propose that we attempt to negotiate a ban on civil defense and industrial protection with the Soviet Union. Inspection would be extremely easy, it would pose a minimum of interference and would offer little in the way of intelligence-gathering opportunities; this latter point is most significant to the Kremlin. The exposed populations and factories become, as it were, hostages to one's good intentions, and though this view may be regarded as cold-blooded, it strikes this observer as just the opposite. Faced with the choice between reducing casualties in a nuclear exchange and reducing the probability of that exchange taking place at all, my values impel me to the latter course. Others may well choose differently, particularly if they believe in the inevitability of general war with the Soviet Union.

Another way to persuade the adversary that you may be planning to hit first is to do everything possible to locate and pin-point his retaliatory sites. If yours is purely a retaliatory strategy there is no need to find and destroy his missile sites; they will, by then, be vacant and your only "legitimate" desire would be to deliver retribution on his cities and factories, assuming again that you believe that this is a sufficient deterrent and have not succumbed to the doctrine of counter-force "deterrence." 18 Thus, if one of the major purposes of the U-2 overflights was to locate Soviet launching sites and other strategic targets, we were guilty of steps which increase the vulnerability of their retaliatory forces and hence vitiate the stability of the balance of terror. ${ }^{19}$ To quote Professor Morgenstern again, "In order to preserve a nuclear stalemate under conditions of nuclear plenty, it is necessary for both sides to possess invulnerable retaliatory forces. . . . It is in the interest of the United States and Russia to have an invulnerable retaliatory force, and vice versa." ${ }^{20}$ The major point here is that the less vulnerable each side's strike-back capability is, the less inclined he is to strike first; he can, if needs be, absorb a first blow and still retaliate effectively.

bered that while the threat of a first strike against cities may be diplomatically useful, its execution would be of little strategic value. On the matter of casualty-reduction via shelters and/or evacuation, see Herman Kahn, Report on a Study of Non-Military Defense (Santa Monica: Rand Report R-322-RC, July 1958); and House Subcommittee on Military Operations, Hearings ... (Washington: G.P.O., March 1960).

${ }^{17}$ There is no intention here of implying that deterrence is a new concept in military strategy. As long ago as the fourth century, Flavius Vegetius advised his king "Se vi pacem, para bel lum" - if you want peace, prepare for war. But only in the 1950's has it been systemized, codified, provided with a lexicon, and given a game-theoretical base.

${ }^{18}$ It cannot be stressed too often that as one's retaliatory capability moves from counter-city to counter-force, it is (and looks) more and more like a strike-first capability.

${ }^{19}$ There is, however, one justification for trying to pinpoint the other's missile sites: the more accurately they are located, the easier it is to monitor them by radar and other early warning devices, thus maximizing warning time and enhancing your own invulnerability as well as providing better "negative" intelligence.

${ }^{20}$ Op. cit., pp. 74, 76. Italics added. 
There is one final thing that each side can do unilaterally in order to increase the stability of the present and foreseeable equilibrium, and that is to do whatever is possible to maximize both sides' warning time. The reason is simple: the longer you can wait before firing, the more certain you can be that an actual strike has been launched, and the less likely you are to "retaliate" in response to a purely imaginary blow or to highly ambiguous intelligence. Given the present limitations of early warning radar and its inherent inability to discriminate consistently and reliably between meteors, bird formations, and other physical or electronic images on the one hand, and missiles or bombers on the other, if you can delay your response you are less likely to misinterpret a target acquired on the scope. ${ }^{21}$ Of course, if you have installed a hair-trigger response and command system with inadequate checks or restraints in it, you may end up launching a first strike rather than a second one, because you fired on the basis of ambiguous and inconclusive evidence. And if your retaliatory forces are vulnerable, or if your missiles are liquid-fueled or otherwise require a long count-down time, you cannot afford to wait very long for confirmation or disconfirmation. Delay could be fatal, but so could premature response. Thus, it behooves both sides to maximize - by technological and procedural innovation - the length of time they can hold out before firing what is intended to be a retaliatory blow.

Again, there is advantage to both sides in such a situation, as it contributes to the stability of our balance of terror, and each should therefore do what it can to lengthen the other's warning and response time as much as possible. In this vein, it would not be unreasonable for us to give the U.S.S.R. any of our devices which they may not have developed yet and which would stretch out their warning and response time, and give them the opportunity to gather and appraise more reliable "negative" intelligence. Thus if they are behind us in backscatter or other long-range, missile-detecting radar (and the evidence is that they are), it would be prudent to give it to them immediately. Likewise, if we are ahead of them in perfecting the solid-fueled rocket, the initiation of whose firing process can be put off until the last possible moment, it might be wise to make this, too, available to them. These proposals may be unorthodox, but these are dangerous times for adhering to the conventional wisdom. Or, as the game theorists put it, this is not the occasion for playing deterrence as if it were a zerosum game, in which what is advantageous for one is always thought to be disadvantageous for the other. Certain outcomes could be advantageous to each, just as some could be disastrous to each. ${ }^{22}$

\footnotetext{
${ }^{21}$ The most dramatic (publicized) example of a mis-reading occurred on October 5, 1960, when the BMEWS station at Thule, Greenland, transmitted a moon echo to NORAD as a "possible" missile attack. Despite the fulfillment of the mechanical requirements for preliminary retaliatory measures, Canadian Air Marshal Slemon "disregarded" the radar return. See the varying interpretations of this event in Boston Traveler, December 13, 1960, p. 40; New York Times, December 23, 1960, p. 10; and Manchester Guardian Weekly, December 1, 1960, p. 13. Also see two popularized stories: John G. Hubbell, "You Are Under Attack - The Strange Incident of October 5," Reader's Digest, April 1961, pp. 37-41; and Peter Wyden, "The Chances of Accidental War," Saturday Evening Post, June 3, 1961, pp. $17 \mathrm{ff}$.

${ }_{22}$ An excellent introduction to this mode of analyzing internation bargaining is Anatol Rapoport, Fights, Games, and Debates (Ann Arbor: University of Michigan Press, 1960).
} 


\section{The Limits of Stability}

Having discussed the wide range of possible means by which each side might unilaterally contribute to the stability of the balance of terror, let us now turn briefly to the limits which do, nevertheless, exist. The foregoing examination might persuade the reader that if each side will only demonstrate sophistication, prudence, and awareness of the psychological impact of one's own acts, we can continue to live quite safely under the umbrella of a stable deterrent. But such, alas, may be too optimistic a conclusion. Let us examine, briefly, the sorts of assumptions one must make in order to expect the balance to remain stable over any significant period of time.

Firstly, one must assume that neither side is already committed to an ultimate attack against the other. If one side is so committed, the other's deterrent and prevent-the-war policies must give way to greater emphasis on win-the-war policies, thus contributing to a growing instability of the balance. That some Soviet and Western planners are willing to subordinate prevent-the-war to winthe-war policies indicates that they do, in fact, accept the inevitability of an enemy strike.

Secondly, one must be convinced that the two super-powers are - and will remain - in complete control of the situation, and that no third power could or would intervene to upset the equilibrium. This conviction presumes, in turn, that those that are likely to acquire a nuclear-missile capability will exercise the same restraint as we, the British, and the Soviets, and that those who will not exhibit such restraint are not going to acquire that capability. ${ }^{23}$

Thirdly, faith in the stable deterrent presupposes that at all times each side will find the military stand-off preferable to any other state of affairs and will never have any military, political, economic, or psychological incentive for upsetting it. The validity of this broad assumption rests, in turn, upon several more specific - and equally dubious - ones. A key premise is that at no time will either side find itself in a situation in which it preceives a military advantage in surprise attack. The corollary of this is that neither will find itself in a situation which leads it to believe that the other preceives an advantage to itself in striking first. The former development could produce a "preventive" strike, and the latter could lead to a pre-emptive strike. ${ }^{24}$ As to the developments which could upset these two assumptions, there are several which come readily to mind.

One could be the acquisition of an important new weapons system. For example, if one side were to develop a highly effective defense against missiles, it might calculate that enough of the retaliatory blow could be intercepted to make the cost of victory acceptably low. ${ }^{25}$ Again, the corollary is that if one side

\footnotetext{
${ }^{23}$ Several implications of the Nth power problem are explored systematically in Arthur Lee Burns, The Rationale of Catalytic War (Princeton: Center of International Studies, 1959 [Research Memo No. 3]).

${ }^{24}$ By preventive strike we refer to one initiated in order to deprive the adversary of the first strike which you expect him to launch at some future date. Pre-emptive strike refers to one launched on the basis of a belief that the adversary is just about to, or already has, launched an attack upon you.

${ }^{25}$ It should be remembered that "acceptability" of damage is a function of industrialization, population size and concentration, and national values; if China's value system is revealed in cur-
} 
discovered (or believed) that the other was about to produce such a weapon, it would (in the atmosphere of continuing hostility and suspicion) have to assume that the breakthrough would eventually be exploited either militarily or diplomatically. If the expected exploitation were thought to be military, there would be tremendous incentive for the other to strike first, before he is completely disadvantaged. And if the anticipation of exploitation were thought to be primarily diplomatic blackmail, he might likewise be willing to risk all in order to avoid being so threatened later. Another technological breakthrough that could produce these consequences is in the target detection realm. When (not if, but when) one side is able to pin-point most of the other's missile sites probably via reconnaissance satellites - it will probably be in a position to obliterate enough of their retaliatory capability to make the costs of victory acceptable. In the same vein, as ASW (anti-submarine warfare) techniques improve, even the Polaris system becomes increasingly vulnerable to detection and destruction, and hence decreasingly able to provide the stable deterrent. Though underwater detection is most difficult and several years of work are required for a breakthrough, the event seems almost inevitable, and this "ultimate weapon" then joins the ranks of its many predecessors. ${ }^{26}$

Another development which could upset the stability assumption would be the acquisition by one side of such political or economic assets as to permit it to dictate terms to the other. Faced with this gradually evolving prospect, the loser would have considerable incentive to fight now rather than be "nibbled to death" by diplomatic threat later.

In addition to the assumptions which must be made if one wants to posit the continuing lack of incentive for launching a preventive blow, there are those which apply to continuing restraint regarding a pre-emptive blow, and these are only a little less encouraging. Most crucial here is the assumption that at no time will either side engage in a test, practice, alert, maneuver, or deployment which has enough of the earmarks of a surprise attack to convince the other that it has no choice but to "pre-empt." There are many equivalents of the meteors or geese on the radar scope, and if they not only look like planes or missiles on radar, but turn out to be such, and seem to be headed for your territory, the incentive to get your "strike-back" forces launched will be compelling. And missiles, unlike planes, are not recallable; there is no "fail-safe" rendezvous point at which they can turn around and come home.

Also in the category of events which might lead to what the initiator thinks of as a pre-emptive or forestalling blow, is that which produces a series of steps of lethal reciprocity. For example, if one side were to intercept signals believed to be the order for surprise attack, and it merely went into an intermediate condition of alert, the other might well interpret the alert as the beginning of a possible at-

rent behavior, and she suffers from (or enjoys?) overpopulation during the period between acquisition of nuclear-missile capability and intensive industrialization, she might be willing to take losses far greater than those acceptable to the U.S.S.R. or the NATO powers.

${ }^{26}$ See House of Representatives, Committee on Science and Astronautics, Ocean Sciences and $\mathrm{Na}$ tional Security (Washington: G.P.O., 1960); and Norman Precoda, On the Fleet Ballistic Missile System ... (Santa Barbara: General Electric Co., October 1958). 
tack, and thus go into its own form of alert. With this, or any of the events cited above, we can quickly get into a self-generating sequence whose ultimate result is mutual devastation. ${ }^{27}$ Whether one talks of communication breakdown, electronic illusion, aggressive alert, or the disobedient or incompetent officer, one can see a range of possible ways in which the delicate balance can be upset. It is important to appreciate that these possibilities are being prepared against and that there is still more which both sides can do to prevent accidental war; furthermore, the command and control procedures are laden with a multitude of onerous checks, vetoes, and negators. Thus, the probability of these specific events which can lead to accidental pre-emption is not particularly high, but it is certainly well above zero, and that should be a matter of concern to all.

\section{Stable Deterrence - Stepping Stone to Disarmament}

In the central part of this article, we examined the possible techniques by which we and the Soviets - alone or together - might contribute to the stability of our present and foreseeable military standoff. The major technique is, of course, the acquisition of mutually invulnerable deterrent forces, but it should by now be evident that there is no such thing as an invulnerable deterrent. All weapon systems are vulnerable; it is just that some are less vulnerable than others. And whatever technique one employs to minimize vulnerability, there are always other less attractive implications. Hardening, dispersal, distance, and numbers are costly, time consuming, lead to a quantitative race, and may well call forth heavier attacks than might otherwise be thought necessary. Mobility and concealment are likewise costly, lead to their own kind of tension-generating weapons race, can never be fully successful, and are inevitably susceptible to technological upset.

Turning from the elusive search for invulnerability to the pursuit of active defense and early warning systems, we likewise find ourselves confronted with a chimera. If we do not have an effective air defense, our retaliatory forces are more vulnerable, but if one of us acquires it before the other, the incentive to strike first rises sharply - on both sides. And in the search for long-range early warning, we find that a system which maximizes warning time enhances stability, but that if it is also good enough to locate the launch site it plays havoc with the other's invulnerability and creates incentives to instability.

Added to these disconcerting limitations and dilemmas in the stable deterrence picture are those of a less technological nature. First of all, we can never forget that every strike-back weapon is also a strike-first weapon; just because some are not particularly good for strike-back, it does not follow that the others are only good for that mission. Secondly, we are often apt, in the fascination of our strategic calculations, to forget that the key decisions in preserving the stable deterrent relationship will be, for some time to come, made by mortal man with all his frailties. How easy it is for us to assume that our "players" are totally rational, completely informed, insusceptible to deviation or breakdown under stress,

${ }^{27}$ For a realistic, but more optimistic, discussion of these and other possibilities, see Herman Kahn, "The Arms Race and Some of Its Hazards," loc. cit., supra. 
unswervingly dedicated to peace and stability, and never will defy orders or violate procedures. Similarly, what confidence we place in our scanning, detection, identification, and communication equipment! If devices as simple as an electric typewriter or transistor radio can break down, how much more likely are our complex computers, facsimile machines, and command networks to do so. Human history is strewn with the wreckage left by failures in man-machine systems; Pearl Harbor was only one of the more dramatic cases.

Finally, one must bear in mind that behind our fallible military personnel and their fallible equipment, lie the most fallible of all human creations - national governments. It may be true that collective decisions tend to be more orthodox and conservative than individual decisions, but orthodox decisions have led many nations in many eras into the inferno of war. How can we be assured that groups under a multitude of stressful and threatening conditions will adhere to the dicta of rationality; and the wrong decision could be made in moments of calm as well as in moments of crisis. Governments are susceptible to a staggering array of forces, many of which lead in destructive directions. Moreover, as has already been suggested several times, there will certainly be occasions in the next few years when the most "rational" decision some governments can take is to launch the very strike which plunges all of us into nuclear war.

The point to be made is that the principle of deterrence via threatened reprisal is ancient, and that it has enjoyed only a very limited success. The new deterrence is somewhat more carefully calculated than its predecessors and its probability of effectiveness may perhaps be a shade higher, but the implications of its failure are infinitely greater than in any other period. Certainly we must strive to build as much stability as we can into our bipolar deterrent, but it will never be enough. One can only look with amazement upon the enthusiasm and confidence with which the stable deterrent strategy has been embraced.

What is particularly distressing is not that there is such widespread faith in the stability of deterrence, but that this faith is being increasingly shared by the disillusioned proponents of disarmament. All of the arguments which the latter used to level at the gross armers are only slightly less applicable to the sophisticated deterrers, yet because disarmament has encountered such rough going and because the deterrers speak like reasonable and peaceful men, the champions of the only approach which offers any long-range prospects have succumbed to the newest nostrum of the military metaphysics.

This is not a call for the disarmament advocates to return to their original innocence and purity, nor for the seekers of the stable deterrent to throw up their hands in despair. Rather what is urged is that both recognize the limits and transitory nature of such a strategy, and pursue it for what it is - a temporary state of affairs which may enable us to buy time. What we and the other powers do with that time is crucial. As each new weapon system moves from drawing board to operational status, it becomes increasingly difficult to control, limit, or eliminate. First, we let control of the nuclear warhead elude our grasp; then the ICBM; and now the space satellite and BCR systems are fast becoming uncon- 
trollable. How many more such errors can the nations make before it is too late? In the long run only comprehensive and enforced disarmament can offer any genuine national security, and it may well involve no more effort, ingenuity, and cost than the more modest goal. Stable deterrence - yes, but only as a way station to comprehensive disarmament under supranational control. 